\title{
Metabolic Syndrome in Type 1 Diabetics: Prevalence and Clinicobiological Features
}

\author{
Y. Htira, A. Mankai, Z. Hadj Ali and F. Ben Mami
}

\section{ABSTRACT}

Background: Because of the world obesity epidemic, some type 1 diabetics exhibit clinical-biological features of metabolic syndrome. Few studies have investigated the association between this syndrome and this type of diabetes.

Aim: To estimate the prevalence of metabolic syndrome in type 1 diabetics and to study the relationship between this syndrome and the clinicalbiological profile of these patients.

Methods: We carried out a cross-sectional study, involving type 1 diabetics, monitored at the National Institute of Nutrition in Tunis. All of these patients underwent a clinical examination and laboratory workup.

Results: We included 150 patients. The mean age of the patients was 31.25 \pm 10.3 years. Women represented $54 \%$ of the patients. Abdominal obesity was found in $61.7 \%$ of women and $14.5 \%$ of men. The metabolic syndrome was found in $30.7 \%$ of patients, with a female predominance $(48.1 \%$ vs. $10.1 \%$ in men, $p<0.001)$. Comparing the two groups with and without metabolic syndrome, the latter was significantly correlated with sedentary lifestyle, daily insulin dose, hypertriglyceridemia, hypoHDLcholesterolemia and arterial hypertension, but not correlated with the age of the patients, the duration of diabetes or the glycemic control.

Conclusion: This work reveals a high prevalence of metabolic syndrome in type 1 diabetics in whom it seems relevant to look for the components of this syndrome, each considered to be a cardiovascular risk factor in its own right.

Keywords: Diabetes, dyslipidemia, metabolic syndrome, overweight.

Submitted: July 26, 2021

Published: October 27, 2021

ISSN: 2593-8339

DOI: $10.24018 /$ ejmed.2021.3.5.990

Y. Htira*

Institut Natinal de Nutrition et de Technologies Alimentaires de Tunis, Tunisia.

(e-mail: yosrahtira@gmail.com)

A. Mankai

Institut Natinal de Nutrition et de Technologies Alimentaires de Tunis, Tunisia.

(e-mail: aminamankai@gmail.com)

Z. Hadj Ali

Institut Natinal de Nutrition et de Technologies Alimentaires de Tunis, Tunisia.

(e-mail: hadjalinbz@gmail.com)

F. Ben Mami

Institut Natinal de Nutrition et de Technologies Alimentaires de Tunis, Tunisia.

(email: benmamifaika@yahoo.fr)

*Corresponding Author

\section{INTRODUCTION}

Since the first description of the metabolic syndrome by Reaven in 1988, several studies have established the relationship between this syndrome and cardiovascular risk. Many of these studies have focused on the metabolic syndrome in the general population, in obese subjects and in patients with type 2 diabetes. Very little data is available on the presence of the metabolic syndrome or its components in patients with type 1 diabetes.

\section{AIMS}

In this work, we set out to estimate the prevalence of the metabolic syndrome in a group of type 1 diabetic patients and to study the relationship between this syndrome and the clinical-biological features of the patients.

\section{Methods}

We carried out a cross-sectional study on type 1 diabetic patients aged 18 to 65 , known to have diabetes for at least 6 months, the age of discovery of diabetes was less than 35 years, all treated with insulin from the discovery of the diabetes.

In patients aged 30 to 35 years at the time of diagnosis, we required positivity for one of the type 1 diabetes antibodies (anti GAD 65, anti IA2 and ICA antibodies).

Pregnant women, ethylic patients, patients with other endocrine pathology, patients with end-stage renal disease and patients treated with corticosteroids were excluded from this study.

All the patients underwent an interview specifying the general characteristics (age, habits, profession, physical activity), personal and family pathological history (type 1 and 2 diabetes, hypertension, dyslipidemia, cardiovascular events, and obesity), disease history (age at discovery of diabetes, circumstances of discovery, acute complications like ketoacidosis since diabetes diagnosis, type of insulin and current insulin doses).

The patients also benefited from a dietary survey, specifying the caloric intake as well as macronutrients and micronutrients intakes.

All patients underwent a physical examination, including anthropometric measurements: waist circumference, weight and height allowing the calculation of the body mass index 
(the weight in kilograms divided by the square of the height in meters).

The biological assessment consisted of fasting and postprandial glycemia (two hours after the start of breakfast), glycated hemoglobin $(\mathrm{HbA} 1 \mathrm{c})$, lipids concentrations (total cholesterol, HDL-cholesterol, triglycerides, and LDLcholesterol which was calculated using Friedwald's formula).

We have adopted the consensus definition of metabolic syndrome (MS) according to the "International Diabetes Federation" (IDF, 2005):

${ }^{*}$ Mandatory criterion:

Waist circumference $\geq 94 \mathrm{~cm}$ in men and $\geq 80 \mathrm{~cm}$ in women.

* With at least two of the following criteria:

- Fasting blood glucose $\geq 1 \mathrm{~g} / 1$ or type 2 diabetes.

- Triglyceridemia $\geq 1.5 \mathrm{~g} / 1$ or specific treatment of the lipid abnormality.

- HDL-cholesterolemia $<0.4 \mathrm{~g} / 1$ in men and $<0.5 \mathrm{~g} / 1$ in women, or specific treatment of the lipid abnormality.

- Systolic blood pressure $\geq 130 \mathrm{mmHg}$ and / or diastolic $\geq 85 \mathrm{mmHg}$ and / or antihypertensive treatment.

\section{Results}

We included 150 patients with a mean age of $31.25 \pm 10.3$ years with extremes ranging from 18 to 62 years. Women represented $54 \%$ of our patients. Only $9.3 \%$ of patients were under 20 years old, almost two thirds were between 20 and 40 years old and subjects over 50 years old accounted for $7.3 \%$ of patients.

The mean duration of diabetes was $12.7 \pm 9.2$ years with extremes ranging from 7 months to 41 years. It was statistically comparable for both sexes $(\mathrm{p}=0.1)$ with $12.3 \pm 9.5$ years in men and $13 \pm 9$ years in women. The mean $\mathrm{HbAlc}$ level was $10.1 \pm 2.3 \%$ with extremes ranging from 6 to $17.9 \%$, with no statistically significant difference between the two sexes $(\mathrm{p}=0.3)$.

Sedentary patients represented $41.7 \%$ of the study population and only $12.9 \%$ had significant physical activity. The level of physical activity was comparable for both sexes $(\mathrm{p}=0.1)$.

The average weight was $68.7 \pm 12.6 \mathrm{Kg}$ with extremes ranging from 40 to $106 \mathrm{Kg}$. The average Body Mass Index (BMI) was $24.65 \pm 4.1 \mathrm{Kg} / \mathrm{m}^{2}$ with extremes ranging from 16.5 to $40.3 \mathrm{Kg} / \mathrm{m}^{2}$. Women had a significantly higher BMI than men $(\mathrm{p}=0.01)$.

More than two-thirds of the men had a normal BMI $(69.1 \%)$, in contrast more than half of the women $(51.3 \%)$ were overweight. The difference was statistically significant $(\mathrm{p}=0.045)$. The mean BMI was significantly higher in patients with metabolic syndrome $(\mathrm{p}<0.001)$.

An increase in the waist circumference was found in $61.7 \%$ of women, and in $14.5 \%$ of men. The difference was significant $(\mathrm{p}<0.001)$.

Metabolic syndrome was found in $30.7 \%$ of our patients.

Apart from abdominal obesity and diabetes, low HDL cholesterol was the most common factor $(76.1 \%)$ in patients with metabolic syndrome, arterial hypertension was second (47.8\%). Only 3 patients $(6.5 \%)$ had all the criteria for the MS.
There was no correlation between the MS and the mean age of the patients, which was $30.6 \pm 10$ years in patients with metabolic syndrome versus $31.5 \pm 10.6$ years in patients without MS $(\mathrm{p}=0.6)$.

MS was significantly more common in women; it was found in $48.1 \%$ of women against $10.1 \%$ of men $(p<0.001)$.

More than half of patients with MS (57.5\%) were sedentary, against $34.8 \%$ in patients without MS $(\mathrm{p}=0.05)$.

A family history of type 2 diabetes, high blood pressure, dyslipidemia and obesity was more common in patients with metabolic syndrome; but these results were not statistically significant.

A family history of type 1 diabetes and cardiovascular events did not correlate with the metabolic syndrome.

More than three quarters of patients with MS (77.3\%) were overweight, compared to only $26.4 \%$ in patients without metabolic syndrome. This correlation was statistically significant $(\mathrm{p}<0.001)$.

Age at discovery of diabetes was comparable for patients with and without MS. It was $18.22 \pm 8.3$ years in patients with MS and $18.8 \pm 7$ years in those without MS $(p=0.66)$. We did not find a correlation between the MS and the duration of diabetes which was $12.5 \pm 9.5$ years in patients with metabolic syndrome and $12.8 \pm 9$ years in those without MS $(\mathrm{p}=0.86)$. No correlation was found between metabolic syndrome and glycemic control either.

Patients with metabolic syndrome had mean insulin doses significantly higher than patients without metabolic syndrome $(0.9 \pm 0.33 \mathrm{IU} / \mathrm{kg} /$ day versus $0.8 \pm 0.29 \mathrm{IU} / \mathrm{kg} /$ day; $\mathrm{p}$ $=0.047)$.

Regarding the lipid profile, the mean total plasma cholesterol level was comparable for patients with and without metabolic syndrome $(\mathrm{p}=0.42)$. Hypertriglyceridemia was significantly more common in patients with metabolic syndrome $(p=0.038)$. Patients with metabolic syndrome had significantly higher triglyceride levels compared to patients without metabolic syndrome $(\mathrm{p}=0.036)$.

The mean HDL-cholesterol level was significantly lower in patients with metabolic syndrome $(p<0.001)$. The mean LDL-cholesterol level was comparable for patients with and without metabolic syndrome $(\mathrm{p}=0.81)$.

Mean systolic blood pressure was significantly higher in patients with metabolic syndrome. In contrast, the mean diastolic blood pressure was comparable for the two groups.

Regarding microvascular complications of diabetes, retinopathy and nephropathy were more common in patients with metabolic syndrome, but the difference was not statistically significant ( $p=0.54$ and $p=0.17$, respectively).

Diabetic neuropathies, peripheral and vegetative, were more frequent in patients with metabolic syndrome, without significant difference.

Regarding atherosclerotic disease, there was no correlation between metabolic syndrome and coronary artery disease $(p=0.9)$. Lower limb arteritis was more common in patients with metabolic syndrome, with no significant difference $(\mathrm{p}=$ 0.17).

As far as the patients' nutritional status is concerned, the average caloric intake was comparable for patients with and without metabolic syndrome as well as its protein, carbohydrate, and fat distributions. In contrast, the mean cholesterol intake was significantly higher in patients without 
metabolic syndrome. Intakes of saturated and polyunsaturated fatty acids were comparable for the two groups, but intake of monounsaturated fatty acids was significantly higher in patients with metabolic syndrome. There was no significant difference between the two groups in the average daily fiber intake.

The relationship between metabolic syndrome and nutritional status is shown in Table I.

TABLE I: RELATIONSHIP BETWEEN METABOLIC SYNDROME AND NUTRITIONAL STATUS

\begin{tabular}{cccc}
\hline & Patients with & Patients & P \\
& MS & without MS & \\
\hline \hline Caloric intake (Kcal/day) & $2063 \pm 761$ & $2379 \pm 801$ & 0.07 \\
$\begin{array}{c}\text { Proteins intake \% } \\
\text { Lipids intake \% }\end{array}$ & $11.7 \pm 1.7$ & $12.2 \pm 2.6$ & 0.3 \\
carbohydrates intake \% & $36.5 \pm 10.7$ & $36.3 \pm 8$ & 0.9 \\
Cholesterol intake & $51.5 \pm 9.5$ & $51.4 \pm 4$ & 0.9 \\
$\quad$ (mg/day) & $75.2 \pm 81$ & $184.2 \pm 192$ & 0.005 \\
$\begin{array}{c}\text { Saturated fatty acids } \\
\text { (\% /lipid intake) }\end{array}$ & $25.4 \pm 6$ & $27.4 \pm 8.8$ & 0.2 \\
$\begin{array}{c}\text { Monounsaturated fatty } \\
\text { acids (\% /lipid intake) }\end{array}$ & $53.4 \pm 10$ & $46 \pm 17$ & 0.035 \\
$\begin{array}{c}\text { Polyunsaturated fatty } \\
\text { acids (\% /lipid intake) }\end{array}$ & $21 \pm 9$ & $26.4 \pm 16$ & 0.08 \\
Fibres intake (g/day) & $18.5 \pm 5$ & $20.1 \pm 7$ & 0.2 \\
\hline \hline
\end{tabular}

\section{DISCUSSION}

In our study, metabolic syndrome was found in $30.7 \%$ of patients with type 1 diabetes according to the 2005 IDF criteria.

According to Harzallah, in a study including 863 subjects living in Tunis in 2006, the prevalence of metabolic syndrome according to IDF criteria was $45.5 \%$ [1]. On the other hand, the American studies "Pittsburg Epidemilogy of Diabetes Complications Study experience" [2] and "Diabetes Control and Complications Trial" (DCCT) [3], which referred to the IDF criteria, found prevalences between $8 \%$ and $22 \%$ in type 1 diabetics. In the Pittsburg study the prevalence of metabolic syndrome in type 1 diabetics was $8 \%$ according to the IDF definition. The prevalence of metabolic syndrome varies from population to population. This certainly depends on genetic factors, dietary habits, the population studied as well as the diagnostic criteria adopted to define the metabolic syndrome.

In our study, we found that in type 1 diabetic patients with metabolic syndrome, low HDL-C levels was the most common criterion $(76 \%$ of patients with metabolic syndrome). High blood pressure came second (48\% of patients with metabolic syndrome), and hypertriglyceridemia came last ( $17 \%$ of patients with metabolic syndrome).

These results agree with those of the DCCT study with regard to the predominance of low HDL-C levels compared to other elements of the metabolic syndrome [3].

In type 1 diabetics, a positive correlation between age and the presence of metabolic syndrome has been found by several studies [4]-[7]. However, the DCCT study including 1337 type 1 diabetics and using the IDF (2005) criteria for metabolic syndrome, did not report this correlation [3].

We did not find a correlation between metabolic syndrome and age in our type 1 diabetic patients. Our result could be explained by the fact that the majority of our patients were relatively young (between 20 and 40 years old) and that only a fifth of the patients were over 40 years old.

"The Pittsburgh Epidemilogy of diabetes complications study experience", a prospective 10-year study including 514 patients with type 1 diabetes, and which referred to the IDF criteria for the definition of the metabolic syndrome, reported a clear predominance of the metabolic syndrome in women compared to men ( $86 \%$ and $14 \%$ respectively) [2].

In our study, this correlation was found, with a prevalence of metabolic syndrome of $48.1 \%$ in women and $10.1 \%$ in men.

The female predominance of metabolic syndrome in our study can be explained by significantly higher BMI and waist circumference in women, compared to men.

In addition, regular physical exercise has been shown to improve most components of the metabolic syndrome [8]. According to a Japanese study comparing two groups of people without diabetes, active and sedentary, the prevalence of metabolic syndrome was significantly lower in active subjects [9]. This result was also observed in type 1 diabetics according to the "Pittsburgh Epidemilogy of diabetes complications study experience" [2].

In our study, metabolic syndrome was more common in sedentary subjects.

Many studies that inverstigated the metabolic syndrome in type 1 diabetics have found a higher BMI in patients with metabolic syndrome compared to those without metabolic syndrome [2]-[6], [10]. We have found the same result.

According to Thorn [20] and Jarvinen [11], [12], the prevalence of metabolic syndrome increased in type 1 diabetic patients with poor glycemic control. Other studies have not found this correlation in type 1 diabetics [2], [4], [6], [13]. We also did not find a relationship between glycemic control and metabolic syndrome.

The lack of a positive relationship between metabolic syndrome and glycemic control in our study can be explained by insufficient estimation of glycemic control in our patients. Indeed, we noticed, in the cross-sectional study that we conducted, a single value of $\mathrm{HbAlc}$ to estimate glycemic control.

McGill [6] and Ghosh [10] found a significant association between the metabolic syndrome and the daily insulin dose in type 1 diabetics. According to the "Pittsburg Epidemiology of Diabetes Complications Study experience", the metabolic syndrome was not correlated with the daily insulin dose in type 1 diabetics [2]. In our study, daily insulin doses were significantly higher in patients with metabolic syndrome.

According to several studies in patients with type 1 diabetes, the triglyceride level in patients with metabolic syndrome compared to those without metabolic syndrome was significantly higher [2], [5], [6], [10], [13], [14] and the HDL-C level was lower [2], [5], [10], [13]. In contrast, Santos et al. did not find a correlation between metabolic syndrome and HDL-C level [14].

Total cholesterol level was higher in type 1 diabetics with MS according to several studies [2], [5], [6], [10]. Gosh and Santos [15] found higher LDL-C levels in type 1 diabetic patients with metabolic syndrome, but without significant difference.

In our study, hypertriglyceridemia and low HDL-C levels were more common in patients with metabolic syndrome. In 
fact, these two abnormalities are parts of the MS as defined by the IDF 2005. In addition, low HDL-C was the most common factor observed in patients with metabolic syndrome. In contrast, we noticed that total cholesterol and LDL-C levels were comparable for patients with and without metabolic syndrome.

A positive correlation between metabolic syndrome and arterial hypertension was found in type 1 diabetics by Thorn et al. in the Finn Diane study [5] and by McGill in an Australian study [6]. In contrast, Báez et al. in a Chilean study, did not find a correlation between metabolic syndrome and high blood pressure [13].

In our study, this positive relationship was found as far as the systolic blood pressure was concerned. It was significantly higher in patients with metabolic syndrome. The mean diastolic blood pressure was comparable for the two groups.

Regarding microvascular dysfunction, the majority of studies investigating the metabolic syndrome in type 1 diabetics have not reported a correlation between diabetic retinopathy and the presence of metabolic syndrome [3], [6], [10], [14], [16], [17]. In contrast, according to Chillarón et al. in a prospective Spanish study including 91 type 1 diabetic patients, diabetic retinopathy was significantly more common in type 1 diabetic patients with metabolic syndrome [4].

In our study, diabetic retinopathy was more common in patients with metabolic syndrome, but the difference was not statistically significant.

According to several studies, diabetic nephropathy was significantly more common in type 1 diabetic patients with metabolic syndrome, compared to those without it [2], [4], [6], [10], [16].

Kilpatrick in the DCCT study [3] and Santos in a Brazilian study [14], adopting the IDF criteria for the definition of metabolic syndrome, did not find this correlation in type 1 diabetics.

In our study, we observed a higher prevalence of diabetic nephropathy among patients with metabolic syndrome, but without significant difference.

The lack of a positive relationship between the metabolic syndrome and diabetic nephropathy in our patients could be explained by the short duration of diabetes (12.7 years).

Several studies have reported a positive association between metabolic syndrome and diabetic neuropathy in patients with type 2 diabetes [18], [19], as well as in type 1 diabetes [4], [6], [10].

According to a European study including 3250 type 1 diabetic patients, patients with diabetic neuropathy had higher insulin resistance, measured by "eGDR" (estimated Glucose Deposal Rate) [20].

In our study, diabetic neuropathy was more common in patients with metabolic syndrome but without significant difference. Unlike diabetic retinopathy and diabetic nephropathy, where we used objective criteria, diabetic neuropathy was assessed on clinical criteria, some of which were subjective, which could underestimate the prevalence of diabetic neuropathy.

In type 1 diabetics, the relationship between metabolic syndrome and coronary artery disease remains controversial. Some studies have reported a positive relationship [5], [10], [16], others have observed a predominance of coronary heart disease in type 1 diabetic patients with metabolic syndrome but without a statistically significant difference [3], [4], [6].

In our series, we did not find a correlation between metabolic syndrome and coronary artery disease.

Our results can be explained by the limitations of the screening methods. Indeed, we relied on clinical criteria and the resting ECG. A stress test or a stress ultrasound would have been able to diagnose cases of silent myocardial ischemia.

Regarding lower limbs arterial disease, in type 1 diabetics, the results of the different studies were not consistent.

McGill et al. have reported a positive relationship [6]. In contrast Chillaron et al. noted a higher frequency of lower limb arterial disease in type 1 diabetics with metabolic syndrome, but without a statistically significant difference [4]. Our findings were similar to that of Chillaron [4].

Regarding food intake, according to the "Pittsburgh Epidemiology of diabetes complications study experience",

the metabolic syndrome was correlated with daily caloric intake in type 1 diabetic patients [2]. In our study we did not find a correlation between the metabolic syndrome and the following intakes: total calories, proteins, carbohydrates, lipids, saturated fatty acids, polyunsaturated fatty acids and fibers. On the other hand, the mean cholesterol intake was significantly higher in patients without metabolic syndrome. The monounsaturated fatty acids intake was significantly higher in patients with metabolic syndrome.

\section{CONCLUSION}

Our study reveals a high prevalence of metabolic syndrome in type 1 diabetic patients, often considered to be normal weight, and a positive correlation with female sex, sedentary lifestyle, overweight, increased waist circumference, hypertriglyceridemia, high blood pressure and low HDLcholesterol levels.

Our results should encourage the screening of metabolic syndrome, not only in obese subjects and type 2 diabetics, but also in type 1 diabetics, who have an increasing prevalence of abdominal obesity.

Despite the lack of correlation between the presence of metabolic syndrome and macrovascular complications in our patients, the high prevalence of this syndrome proves the increased cardiovascular risk in type 1 diabetics; prospective studies in this population could better investigate this risk.

\section{REFERENCES}

[1] F. Harzallah, H. Alberti and F. Ben Khalifa, "The metabolic syndrome in an Arab population: a first look at the new International Diabetes Federation criteria," Diabetic Medicine 23:441-4, 2006.

[2] G. Pambrianco, T. Costacou and TJ. Orchard, "The Prediction of major outcomes of type 1 Diabetes: a 12-Year Prospective evaluation of three separate definitions of the Metabolic Syndrome and their components and estimated glucose disposal rate," Diabetes Care 30:1248-54, 2007.

[3] E. Kilpatrick, AS. Rigby and SL. Atkin, "Insulin Resistance, the Metabolic Syndrome, and Complication Risk in Type 1 Diabetes," Diabetes Care 30:707-12, 2007.

[4] J. J. Chillarón, J. A. Flores, A. Goday, D. Benaiges, M. J. Carrera, J. Puig and J. Pedro-Botet, "Metabolic Syndrome and type-1 Diabetes Mellitus: prevalence and associated factors", Revista Española de Cardiología (English Edition) 63:423-9, 2010.

[5] L. M. Thorn, C. Forsblom, J. Fagerudd, "Metabolic Syndrome in Type 1 Diabetes," Diabetes Care 28:2019-24, 2008. 
[6] M. McGill, L. Molyneaux, S. M. Twigg and D. K. Yue, "The metabolic syndrome in type 1 diabetes: does it exist and does it matter?" Journal of Diabetes Complications 22:18-23, 2008.

[7] Y. Nakashita, M. Nakamura M and A. Kitamura, "Relationships of Cigarette Smoking and Alcohol Consumption to Metabolic Syndrome in Japanese Men," Journal of Epidemiology 20:391-7, 2010.

[8] A. Grimaldi, Traité de diabétologie. $2^{\text {nd }}$ édition. Paris: Flammarion 249-771, 2009.

[9] J. Kim, K. Tanabe, N. Yokoyama, H. Zempo and S. Kuno, “Association between physical activity and metabolic syndrome in middle-aged Japanese: a cross-sectional study," BMC Public Health 11:624, 2011.

[10] S. Ghosh, A. Collier, M. Hair and T. Elhadd, "Metabolic syndrome in type 1 diabetes," International Journal of Diabetes Mellitus 38-42, 2010.

[11] H, Yki-Jarvinen and V. A. Koivisto, "Insulin sensitivity in newly diagnosed type 1 diabetes after ketoacidosis and after three months of insulin therapy" Journal of Clinical Endocrinology \& Metabolism 371$8,1984$.

[12] H. Yki-Jarvinen and V. A. Koivisto, "Natural course of insulin resistance in type 1 diabetes", New England Journal of Medicine 315:224-30, 1986.

[13] MS. Bàez, VA. Novik, F. Algerìa, F. Cardemil, R. Riveros and L. C. Bofill, "Sìndromo metabolico en un grupo des patientes diaéticos tipo 1, una nueva variedad de diabetes?" Revista médica de Chile 137:88893, 2009.

[14] C. E. Santos, Y. Schrank and R. Kupfer, "Análise crítica dos critérios de PMS, IDF e NCEP para síndrome metabólica em pacientes portandores de diabetes melito tipo 1"Arquivos Brasileiros de Endocrinologia 53:1096-101, 2009.

[15] M. Modan, H. Halkin, S. Almog, A. Lusky, A. Eshkol, M. Shefi and Z. Fuchs, "Hyperinsulinemia: a link between hypertension, obesity and glucose intolerance", The Journal of Clinical Investigation 75:809-17, 1985.

[16] R. C. Bonadonna, D. Cucinotta, D. Fedele, G. Riccardi and A. Tiengo, "The metabolic syndrome is a risk indicator of microvascular and macrovascular complications in diabetes", Diabetes Care 29:2701-7, 2006.

[17] H. Yki-Järvinen, E. Helve, L. Laatikainen, S. L. Karonen, V. A. Koivisto, "No association between retinopathy and insulin resistance in type 1 diabetes", Acta Endocrinology 111:522, 1986.

[18] B. Isomaa, M. Henricsson, P. Almgren, T. Tuomi T, M. R. Taskinen and L. Groop, "The metabolic syndrome influences risk of chronic complications in patients with type 2 diabetes", Diabetologia 44:114854, 2001.

[19] L. A. Costa, L. H. Canani, H. R. Lisbôa, G. S. Tres and J. L. Gross, "Aggregation of features of the metabolic syndrome is associated with increased prevalence of chronic complications in Type 2 diabetes", Diabetic Medicine 21:252-5, 2004.

[20] S. Tesfaye, N. Chaturvedi, S.E Eaton, J. D. Ward, C. Manes, C. Ionescu-Tirgoviste and J. H. Fuller, "Vascular risk factors and diabetic neuropathy," New England Journal of Medicine 352:341-50, 2005. 